\title{
Response of Pharmaceutical Companies to Biotechnology: Structure and Business Models
}

Working Paper No. 33

Bruce Rasmussen

\section{Pharmaceutical Industry Project Working Paper Series}

August 2007

Centre for Strategic Economic Studies

Victoria University of Technology

PO Box 14428 Melbourne VIC 8001 AUSTRALIA

Telephone +61399191340

Fax +61399191350

Contact email: bruce.rasmussen@vu.edu.au 


\title{
Response of Pharmaceutical Companies to Biotechnology: Structure and Business Models
}

\author{
Bruce Rasmussen
}

\section{Introduction}

Using the framework of the business model developed in Rasmussen (2007b) this paper presents an outline of the traditional pharmaceutical company business model, and how it has responded to the new biotechnology.

Biotechnology is a radical innovation which has a very different technological regime from the traditional pharmaceutical one. The manner in which biotechnology has been applied to the search for, and development of, biopharmaceuticals is quite different from the traditional approach. This new regime has resulted in the innovation process being substantially conducted by small specialist firms. However pharmaceutical companies have remained innovative, both with respect to the traditional small molecule based technological trajectory but also in their adjustment process to the new technology.

The process of drug development is lengthy, uncertain and costly. Work by DiMasi and Grabowski (2007) indicates that to date neither the cost, nor the development period, of biopharmaceuticals was much different from than that for traditional pharmaceuticals. Accordingly the economics of biopharmaceutical development remains much the same as for traditional pharmaceuticals. To the extent that the economics of traditional pharmaceutical production have encouraged large fully integrated firms, then the economics of biopharmaceutical production may similarly favour large firms.

\section{The traditional pharmaceutical company business model}

In Rasmussen (2007b) the purpose of the business model was described by Chesbrough and Rosenbloom (2002) as providing the construct that mediates the value creation process between the technical and economic domains, selecting and filtering technologies and packaging them into particular configurations to be offered to the market. One of the major tasks for pharmaceutical firms is selecting drug discovery and other technology projects for continued investment while rejecting or dispensing with others. In an open innovation model, firms would be expected to seek knowledge externally and licence out knowledge that did not fit their business model.

In the traditional business model, pharmaceutical companies adopted the closed innovation model (Chesbrough in Chesbrough et al. 2006). They conducted the majority of their research internally which provided the basis for the development of their own drugs (Chandler 2005). Firms conducted basic research confident of their downstream commercialisation capabilities (Rosenberg 1990). Serendipitous discoveries that did not fit the therapeutic interests of the particular pharmaceutical firm were more likely to be cancelled, rather than licensed out.

The next sections discuss the components of the business model in turn using the theoretical framework (Rasmussen 2007b). 


\section{Value Proposition}

Chesbrough and Rosenbloom (2002) define the value proposition as the value created for users by the offering based on the technology. For the user, the value proposition of the pharmaceutical companies has been quite powerful. Modern scientifically based medicines have had a major impact on saving and improving the quality of life. In the post war period, pre biotechnology, this was based on the success of a range of new drugs including antibiotics, contraceptives, vaccines and anaesthetics. The value proposition has been supported by the increasingly scientific based knowledge accumulated by pharmaceutical firms and the predictability of the outcomes of the drugs. This has been assisted in the public mind by clinical testing processes and by the certification provided by the FDA and/or equivalent agencies in other countries.

A difficulty of the definition of the value proposition as applied to pharmaceutical companies is that the patient (the 'user') does not typically decide which drug is to be purchased. There are many actors that bear on the decision to purchase a particular drug and the value proposition developed by the pharmaceutical company must be multifaceted to appeal to each of these 'non user' decision makers.

Firstly the major innovative drugs can not be purchased without a prescription provided by a doctor. The pharmaceutical companies' main selling task has been directed therefore, not at the user, but at physicians. The value proposition to physicians needed to address the scientific basis of the drugs safety and efficacy compared with other similar drugs.

Other actors such as insurers and government agencies controlling the listing of drugs for sale need to be persuaded of the drugs' cost effectiveness. Pharmaceutical companies have considerable pricing power. Each approved drug has, for period, patent protection and typically only limited competition from other drugs treating a particular disease. This monopoly position, when combined with a powerful value proposition has provided the pharmaceutical company with the ability to price well above marginal cost. Insurers and governments agencies have acted as a countervailing power in pricing pharmaceuticals.

For such actors the value proposition needs to extend beyond questions of patient health to the drug's relative performance. If a new drug was to be more expensive, then it needs to demonstrate that its superior performance is worth it, before it is listed on an insurer's formulary. In the US insurance is provided by Pharmacy Benefit Managers (PBMs). For countries such as Australia, in which the government determines whether a drug is to be listed for subsidised use, arguments about its impact on the overall health budget, such as by reducing the length and increasing the effectiveness of a hospital stay, may be important. Findings such as that provided by Lichtenberg (1996), who reported that for the period 1980 to 1992, a \$1 increase in the purchase of pharmaceuticals was associated on average with a \$3.65 reduction in hospitalisation expenditures have become for the pharmaceutical companies, an important part of their value proposition. 


\section{Market Segment and Revenue Model}

\section{Market Segment}

Rather than the consumer of the medicine, the key market segment for the pharmaceutical company has been the physician. A team of sales representatives, so called 'detailers', have been employed by the pharmaceutical firms to meet with physicians to explain the advantages of a particular drug. In this model each major new drug has been launched with a comprehensive and expensive global marketing campaign that involved the full range of marketing tools including media advertising, comprehensive information packs, special events for doctors, conference presentations, and a dedicated sales force.

A further market segment that needed to be persuaded of the value of any new drug has been organisations discussed above, such as insurers, which bring countervailing power to the price negotiations. Not only have these organisations affected sales and prices of new drugs but their insistence on generic substitution once patent protection expired also had a major impact on sales revenue.

\section{Revenue Model}

The revenue model developed by the pharmaceutical companies since the 1970s increasingly depended on the sales of a relatively small number of drugs (Achilladelis 1999). This revenue model became known as the as the 'blockbuster' model (see for instance Mercer Management Consulting 2001). It involves the search for, and distribution of a small number of drugs that achieve substantial global sales (say in excess of $\$ 1000$ million p.a.). The success of this model depends on achieving large returns from a small number of drugs in order to pay for the high cost of the drug discovery and development process for a large number of candidates. Total revenues are highly dependant on sales from a small number of drugs as shown in the table below:

Table 1: Top 10 Bestseller Prescription Drugs in the United States 1998

\begin{tabular}{lllc}
\hline Drug & Use & Manufacturer & Sales $\mathbf{( \$ \mathbf { m } )}$ \\
\hline Prilosec & Anti-ulcerant & Astra Merck & 2,993 \\
Prozac & Antidepressant & Eli Lilly & 2,181 \\
Claritin & Antihistamine & Schering-Plough & 1,848 \\
Lipitor & Cholesterol Reducer & Warner-Lambert/Pfizer & 1,544 \\
Zocor & Cholesterol Reducer & Merck & 1,481 \\
Epogen & Anti-anaemia & Amgen & 1,455 \\
Zoloft & Antidepressant & Pfizer & 1,392 \\
Prevacid & Anti-Ulcerant & TAP & 1,245 \\
Paxil & Antidepressant & SmithKline Beecham & 1,190 \\
Norvasc & Calcium Blocker & Pfizer & 1,086 \\
\hline Total & & & 16,415 \\
\hline Source: IMS America quoted in Landau (1999, p. xx).
\end{tabular}

Table 1 shows the top 10 drugs by sales in the US in 1998 totalling $\$ 16.4$ billion representing $15 \%$ of total sales. Analysis based on more recent data for 2005, shows that the global sales of just 68 drugs by the top 10 companies by global sales represents $58.5 \%$ of their sales, confirming the continuing dependency of the largest firms on the sales of a small number of drugs. 


\section{Value chain and value network}

Prior to the advent of biotechnology, the structure of the value chain of the individual pharmaceutical company was relatively self-contained. Each pharmaceutical company was fully integrated, conducting its own research, development, manufacturing and distribution of its own drugs.

The innovation processes of the large firms were largely closed (Chesbrough 2006). The pharmaceutical industry product pipeline is highly structured, being governed to a large degree by the drug approval process, in which successful drugs are 'moved' down the drug pipeline through a succession of stages - from discovery, to preclinical, clinical, regulatory approval to manufacturing marketing and sales. The value chains of the large firms closely reflected this pipeline with only limited interaction with other firms. Most complementary assets were available in house.

The reasons for this fully integrated structure are suggested by transaction cost economics. These centre on achieving transaction cost economies by integrating transactions that would otherwise have been conducted in the marketplace or by bilateral contract. Whether the transaction was integrated depended on the nature of the assets involved in the transaction (asset specificity), uncertainty and the regularity of the transactions. In general those transactions conducted less frequently, involving more specific assets and having more uncertain outcomes were more likely to be integrated. The nature of the drug discovery and development process provides ample evidence of transactions of this nature. The process of discovering and developing drugs is highly uncertain and involves the investment in assets of great specificity, as evidenced by the high proportion of failures, as well as the highly specific successes. In addition, transactions such as drug candidates passing from one clinical stage to another are clearly irregular.

Moreover the transfer of information about drug development is complex and more efficiently conducted internally (Williamson 1971). Mowrey's study of US manufacturing firms found that the costs of organising innovation inside the firm was lower than attempting to contract for the supply of idiosyncratic knowledge through the market (Mowery 1983 Explorations in Eco History). In addition, by generating knowledge internally, the pharmaceutical company retains all residual property rights (Grossman and Hart 1986; Hart and Moore 1990). The value of any spillover of knowledge between projects that was conducted internally is retained by the pharmaceutical company.

These factors help explain the internal development of the R\&D function, but they leave open the reasons for the internalisation of the sales and distribution function. As their operations evolved, all the large pharmaceutical companies acquired their own distribution function. Companies that previously had little distribution capacity developed their own or in other cases acquired it. For instance, Merck in 1953 acquired Sharpe and Dohme, a company that had a sizeable network (Galambos and Sewell 1995; Galambos and Sturchio 1998).

With only a small number of drugs being approved each year for the whole industry, control over manufacturing and distribution components of the value chain is of critical strategic importance to individual companies. Chandler (1990) has suggested that with the faster throughput and increased productivity arising from economies of 
scale, vertical integration reflects the increased risk of hold up or opportunism by contracted suppliers and distributors. While the manufacturing context of Chandler's views reduces their direct relevance, the scope for opportunism by distributors through inadequate or under-resourced marketing campaigns is nonetheless high. Moreover marketing drugs is knowledge intensive and specialised.

Pharmaceutical companies have also instituted organisational efficiencies to improve the progress of drugs through the value chain and reduce costs. These initiatives may have been difficult or impossible to implement were it not for the vertically integrated structure. For instance Ely Lilly made a significant effort through the 1990s to improve the focus and efficiency of its drug development pipeline (Harvard Business School 1999). These targeted improving speed to market, narrowing the therapeutic focus of its R\&D and creating product based teams to break down the functional silos - development, marketing, sales etc into multi functional teams that were designed to take a single drug through the testing process, launch and subsequent marketing (Burgleman et al. 2001).

\section{Cost structure and profit potential}

One of the tasks of the business model is to estimate the cost structure and profit potential of producing the technology offering, given the value proposition and value chain structure chosen (Chesbrough and Rosenbloom 2002). For analysing pharmaceutical companies this involves understanding the economics of drug discovery, development, manufacturing and distribution. In particular the economics of pharmaceutical companies are governed by high failure rates of drug discovery and development, the high cost of producing an approved drug and as a result the very substantial sunk costs. Once approved, the economic returns from drugs are highly skewed. This follows from the blockbuster revenue model discussed above in which a high proportion of pharmaceutical sales arise from a small number of drugs. Economies of scale and scope have also been found to be important in the drug discovery process and economies of scope in development.

\section{Economies of scale and scope}

Before biotechnology drug discovery relied on large scale, relatively automated processes. For instance, in the absence of a detailed understanding of the underlying reasons for most diseases, large scale screening processes were undertaken to match a large number of drug candidates against a relatively small number of known disease targets.

Henderson and Cockburn (1996), employing firm level data for the period 1960-1988, have shown that there were economies of both scale and scope in drug discovery, indicating that there were gains to be made from spreading various fixed costs, such as investment in common search technologies over multiple projects, as well as gaining scope advantages from applying knowledge gained in one project to another. With respect to drug discovery, Henderson and Cockburn (1996) concluded: 
Cockburn and Henderson (2001) also examined the possibility of economies of scale and scope in the drug development phase. Employing firm level data for 708 development projects for a similar period to that for discovery, 1960-1990, they found that there were economies of scope for development projects, but not economies of scale. Thus firms conducting diverse programs were more productive, suggesting that larger firms are able to efficiently transfer general knowledge about clinical trials across different projects within the firm (Cockburn and Henderson 2001, p1038). These economies of scale and scope have favoured large company structures.

Scale in sales and marketing delivers clear advantage. One indicator of this is that each major new drug is launched with a comprehensive and expensive global marketing campaign that benefits from the infrastructure already established. There is some evidence of increased sales productivity with company size. For instance sales per detailer typically rise with company size (Walton 2001, p. 90). Distribution capability is an important component of firm success. A survey of US pharmaceutical companies suggests that marketing and sales capability accounts for $42 \%$ of the variation in financial performance (Accenture White Paper) (George and Perrone 2001; Blumberg and Perrone 2001).

\section{Sunk Costs}

Drug discovery and development involves very sizeable sunk costs (Baumol and Willig 1981; Sutton 1991), arising from both its high cost and high rate of failure. For every ten drugs entering preclinical trial only one is approved and many more candidates are 'discovered' without entering preclinical trial. Thus on average for each approved drug, a pharmaceutical company expects to invest in nine drug trials that will fail. The cost of a single approved drug, including failures, is about $\$ 1.2$ billion and the average time to gain regulatory approval from time of discovery is 12.5 years. More than half of this cost (\$682 million) relates to the cost of financing the drug development over the extended discovery and clinical trial period. Of the remainder, $\$ 559$ million, an average of $\$ 390$ million or $70 \%$ of the expenditure per successful drug is spent on failed projects and is of little ongoing value to the pharmaceutical company. Thus approximately $70 \%$ of the cost of developing each successful drug is a sunk cost.

\section{Skewed returns}

The returns from drugs once approved are highly skewed. Grabowski and Vernon (2001) have calculated the sales profiles for all new chemical entities (NCEs) for two periods 1980-84 and most recently 1988-92. This showed that half of the value of sales was in the top $10 \%$ of drugs. Comparing the sales profiles for the two periods, Grabowski and Vernon demonstrate that the peak sales achieved by the top decile drugs (\$US3.2billion in the later period) had more than doubled. They also calculated the NPV of drug sales for the earlier period. The NPV of a drug in the top decile of sales in the period 1980-84 was of the order of \$US1000m. They compared the NPV of each decile with the estimated average cost of R\&D for a drug, which they put at just over $\$ 200 \mathrm{~m}$ for that period, showing that only the top $20 \%$ of drugs exceeded this amount.

These formidable economics, particularly those of sunk costs and skewed returns, help explain why pharmaceutical firms need to be of such size to finance and bear the 
risks inherent in drug development. Together with the economies of scale and scope these factors have all tended to encourage pharmaceutical firms to be of large size.

\section{Profitability}

Despite these challenges, simple measures have placed pharmaceutical companies at or near the top of industry profitability rankings (Scherer 1996). However estimating the profitability of pharmaceutical companies is complex, given the long lead times on the return on investment in R\&D. Nonetheless estimates of return on capital which have attempted to measure true economic profitability still tend to suggest above average returns for the industry (Scherer et al. 2000).

This above average profitability arises from a combination of demand and supply considerations. Each drug has a near monopoly position for the life of its patent period or at least until similar drugs enter the market. Given the combination of a powerful value proposition and the availability of reimbursement arrangements through insurers, the price of pharmaceuticals tends to be fairly inelastic (Scherer et al. 2000). Berndt et al. (1995) provides an estimate of -0.69 for anti ulcer drugs over the period 1977 to 1994 . The marginal cost of production is relatively low and pharmaceutical firms have strong incentives to spend heavily on promotion to shift out the demand curve for their product. Promoting drugs through detailers has been shown to be the most effective of a range of promotion activities undertaken (Berndt et al. 1995).

In summary then the cost structure of the pharmaceutical firm is characterised by economies of scale and scope, high sunk costs and relatively low marginal costs of production. High sunk costs arise from the combination of high R\&D costs and high failure rates. Economies of scale and scope favour larger firms with diversified development projects. Returns from approved drugs are highly skewed but sufficient given favourable demand conditions (eg relatively inelastic prices) to provide pharmaceutical companies with at least above average profitability.

\section{Competitive Strategy}

The principal sustainable competitive advantage of pharmaceutical firms has been their core competency (Prahalad and Hamel 1990) in the discovery, development and distribution of innovative pharmaceuticals. The resource based view, with its emphasis on strategic assets as the basis for sustainable competitive advantage, is as relevant to the competitive strategy of the pharmaceutical company as the start up biopharmaceutical firm. The strategic assets may not have been of the same nature, but nonetheless the knowledge assets of the pharmaceutical companies comprising the combination of knowledge and experience in the details of the whole drug discovery, development and distribution were quite formidable. Two points illustrate the centrality of the firms' core competence in pharmaceuticals and the importance of maintaining the value strategic assets.

Firstly the pharmaceutical companies have regularly tested the natural boundaries of the firm, through flirtation with diversification outside the core innovative pharmaceutical business. Pharmaceutical companies have regularly extended their activities into related markets and then drawn back (Chandler 2005). For instance in 1968, Merck purchased Calgon, a large water treatment enterprise and in 1993 
purchased Medco for $\$ 6.6 \mathrm{~m}^{1}$ a large US pharmaceutical benefits management company. Other companies such as Pfizer, expanded into low tech toiletry and other products. In each case the companies shed these diversified activities, retreating to their core competencies in pharmaceutical discovery and development. Merck sold its water treatment business in 1993 and Medco in 2003 (Merck Annual Report 2003). Pfizer refocussed on pharmaceuticals by divesting itself of its other activities in the 1990s (Chandler 2005).

Thus the resource based view has helped to define the corporate boundaries of the major pharmaceutical companies. Investment in other activities has proved to be a less effective use of capital and a distraction to management. It also failed to properly utilise the firms' considerable internal knowledge of the development and sale of pharmaceuticals.

Secondly, while diversifying into related areas has proved to be a strategic error, so too is the mistake of failing to maintain the value of the key strategic asset (Amit and Shoemaker 1993) represented by the number and quality of drug discovery and development projects. Pharmaceutical companies are knowledge intensive companies and the top 10 companies invested in 2005 an average $18.1 \%^{2}$ of their pharmaceutical sales revenue in $R \& D$. Their knowledge of the impact of drugs on disease and the capacity to take drugs through clinical trials is an essential core competency and, providing the necessary investment is maintained, a source of sustainable competitive advantage. There have been periods when companies have failed to maintain the level of investment in R\&D necessary to keep sufficient drug development projects in the product pipeline. Gambardella (1995) outlines the case of SmithKline which failed to reinvest the proceeds of its success with an anti ulcer drug, Tagamet, in upstream research and it was forced to merge with Beecham in 1989. More often than not mergers occur to cover weaknesses in the $R \& D$ pipeline.

\section{Summary: Traditional Pharmaceutical Company Business Model}

Using the framework of the business model, the key characteristics of the traditional pharmaceutical business model have been outlined and explained. Pharmaceutical companies have a powerful value proposition which combined with patent protection provides considerable pricing power. Marketing is complex because the consumer is not the key decision maker for the purchase of drugs and the revenue model is dependent on selling a disproportionately small number of drugs in huge volumes. The discovery and development of pharmaceuticals suffers from very high sunk costs but benefits from economies of scale and scope. The value chain is highly integrated with little interaction with a wider value network. Accordingly the favoured business model is one which is large and fully integrated.

\footnotetext{
${ }^{1}$ New York Times, 20 August 2003.

${ }^{2}$ Author analysis sourced from Pharmaceutical Executive May 2006, Company 10-K SEC filings and annual reports.
} 


\section{The Impact of Biotechnology on the Pharmaceutical Company Business Model}

The next sections analyse the way in which the pharmaceutical company business model has changed in response to the development of biotechnology. It follows the theoretical framework of the business model used in the section above.

The most serious impact on biotechnology has been on the pharmaceutical company value chain and integration into the value network. In other aspects of the business model, the key features are unchanged or in some instances the entry of biopharmaceutical drugs onto the marked is too limited to assess the likely impact.

\section{Value Proposition}

There is little difference between the value propositions for biopharmaceuticals and traditional drugs. For the patient they offer the promise of still better treatment. For the other actors in the purchasing system, such as the physician and other 'gatekeepers', the same issues of efficacy and cost effectiveness apply. The main difference with biopharmaceuticals is that they are generally much more expensive than traditional small molecule drugs and are typically delivered by injection in a clinical setting. Approval for their use is likely to have a higher level of institutional intervention which may limit access.

\section{Market Segment and Revenue Model}

\section{Market Segment}

As indicated in the section on the traditional model, the marketing strategies developed by pharmaceutical companies have been developed to deal with the complexities of the approval process and pricing negotiations with government agencies and private insurers. The skills learned and marketing infrastructure available are likely to be immediately transferable to the marketing of biopharmaceuticals and accordingly many biopharmaceutical companies have entered into distribution arrangements with large pharmaceutical companies.

Many of the biopharmaceuticals developed to date are for use in hospitals, which will require the pharmaceutical companies to adjust the emphasis to niche rather than mass marketing requirements. The existing distribution system is stressed in a number of ways and marketing increasing numbers of biopharmaceuticals may harbinger other changes. For instance pharmaceutical companies have been seeking alternatives to detailers as the major sales channel. The number of detailers has increased to the extent that, even if so inclined, physicians would only be able to allocate less than a few minutes per year to each one (AstraZeneca 2001). Other avenues are being explored such as the greater use of the Internet and more controversially direct-toconsumer advertising.

\section{Revenue Model}

To date biopharmaceuticals have had only a modest impact on the pharmaceutical company blockbuster revenue model. Table 2 lists the 10 largest global pharmaceutical companies by sales of pharmaceuticals for 2005, together with total 
sales of those drugs with global sales exceeding \$US1 billion ('blockbuster'). For comparison the table also lists sales of biopharmaceutical drugs and the number of blockbuster biopharmaceutical drugs.

Table 2: Blockbuster sales by major pharmaceutical companies, 2005

\begin{tabular}{|c|c|c|c|c|c|c|}
\hline Company & $\begin{array}{c}\text { Total } \\
\text { pharma } \\
\text { sales } \\
\end{array}$ & $\begin{array}{c}\text { Total } \\
\text { blockbuster } \\
\text { sales } \\
\end{array}$ & $\begin{array}{c}\text { Blockbuster } \\
\text { ratio }\end{array}$ & $\begin{array}{c}\text { Total no. of } \\
\text { blockbuster } \\
\text { drugs }\end{array}$ & $\begin{array}{l}\text { Biopharma } \\
\text { sales }\end{array}$ & $\begin{array}{c}\text { No. of } \\
\text { biopharma } \\
\text { blockbusters }\end{array}$ \\
\hline & \$billions & \$billions & & & \$billions & \\
\hline Pfizer & 44.28 & 28.28 & 63.9 & 8 & 0.05 & \\
\hline Glaxo & 33.96 & 21.31 & 62.7 & 13 & 0.01 & \\
\hline Sanofi-Aventis & 32.24 & 17.71 & 54.9 & 10 & 2.69 & 2 \\
\hline Novartis & 24.96 & 9.28 & 37.2 & 5 & 0.05 & \\
\hline Astrazeneca & 23.95 & 17.53 & 73.2 & 10 & 0.00 & \\
\hline$J \& J$ & 22.32 & 15.34 & 68.7 & 7 & 0.05 & \\
\hline Merck & 22.01 & 13.59 & 61.7 & 4 & 0.00 & \\
\hline Wyeth & 15.32 & 7.74 & 50.5 & 4 & 0.05 & \\
\hline BMS & 15.25 & 6.08 & 39.9 & 2 & 0.00 & \\
\hline Lilly & 14.65 & 8.78 & 59.9 & 5 & 2.52 & 1 \\
\hline Total Top 10 & 248.94 & 145.61 & 58.5 & 68 & 5.38 & 2 \\
\hline
\end{tabular}

Source: Pharmaceutical Executive May 2006, Company 10-K SEC filings and annual reports.

To date the impact of sales of biotechnology derived drugs on total pharmaceutical sales is quite modest. Of total sales of \$249 billion for the top 10 pharmaceutical companies only $\$ 5.4$ billion $^{3}$ are biopharmaceuticals, of which three are blockbusters accounting for a large share of the total. Two are recombinant insulins and the other is an interferon. For these companies, sales of traditional pharmaceutical blockbusters remain the main feature of their revenue model, with $58.5 \%$ of their pharmaceutical sales represented by only 68 blockbusters. Merck had the highest dependency on blockbusters with a ratio of $73.2 \%$. The highest selling blockbuster was the Pfizer drug Lipitor, with global sales of over $\$ 12.1$ billion, $23.7 \%$ of Pfizer's total pharmaceutical sales.

This illustrates that from a revenue point of view the paradigms of the traditional business model remain of great consequence to the current profitability of the largest pharmaceutical companies. However this revenue model is under threat from the expiration of patent protection of many of the largest selling blockbusters over the next 5 years. Thus pharmaceutical companies are expected to source an increasing proportion of biopharmaceutical drugs.

The main impact on the pharmaceutical business model has been for drug candidates to be sourced from outside the firm either by way of alliance or by acquisition. For the revenue model it means negotiations about royalties and milestone payments that have been of less concern in a more closed innovation system.

\footnotetext{
${ }^{3}$ This sales figure is derived from an analysis of 104 biopharmaceutical drugs approved by the FDA since 1982. Sales are allocated according to the sponsor/applicant. The definition of biopharmaceuticals is derived from Walsh (2002). This analysis forms a significant part of Chapter 15 where the data sources are more comprehensively discussed. The inclusion of Roche and Abbott, ranked 11 and 12 by total sales respectively increases the total 'large pharma' sales of biopharmaceuticals to \$7.7 billion
} 


\section{Value chain and value network}

The impact of biotechnology on the pharmaceutical business model has been perhaps the greatest through its effect on the value chain and value network. The theoretical outline of the business model developed in Rasmussen (2007b) predicted that gaining access to the range of complementary assets would be central to the new business model of the pharmaceutical companies. Pharmaceutical companies have required access to new biotechnologies and the array of associated platform technologies. In doing so the companies have become practitioners of 'open innovation'. As has been be documented in Rasmussen, B. (2007a), they have been active participants in a large number of alliances that have involved a considerable range of both drug discovery and platform technologies.

The individual pharmaceutical company value chains have formed the basis of industry based value networks. As the specialist companies, representing the new technologies, have been integrated into the existing value chain through alliances, a value network between the pharmaceutical companies and the specialist companies has been formed (Cockburn 2004).

An illustration of this how this new value chain developed is shown in Figures 1 and 2, sourced from Granberg and Stankiewicz (2002).

Figure 1. Pharmaceutical Value Chain: Major Specialisations

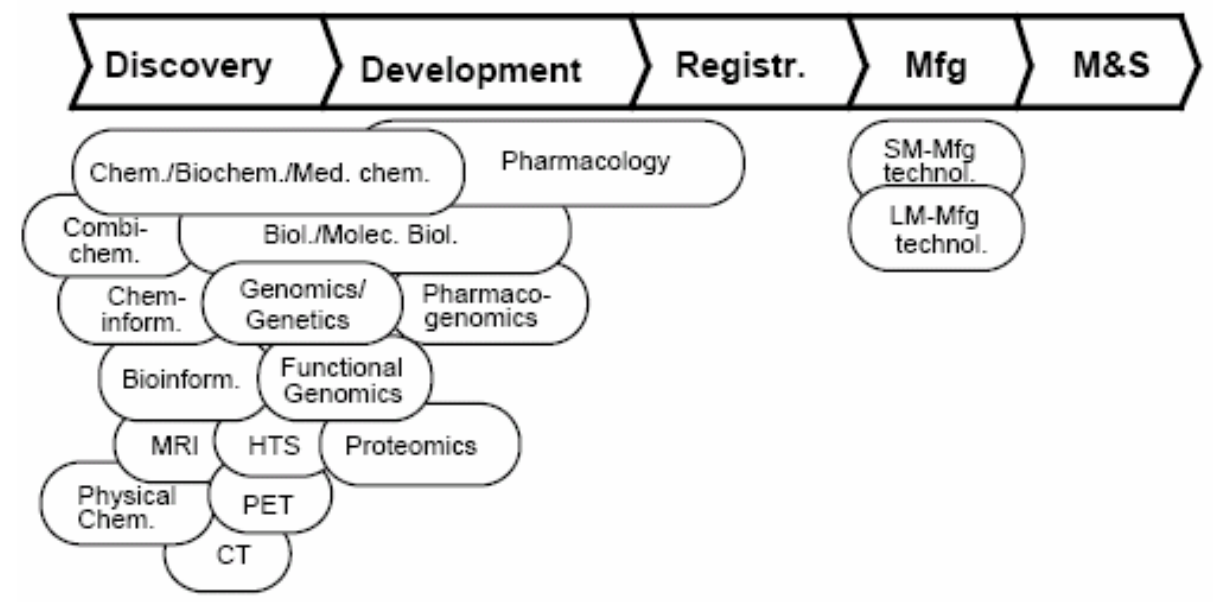

Source: Granberg and Stankiewicz (2002).

Figure 1 illustrates some of the main specialist biotechnologies in the drug discovery and production process such as molecular biology, combinatorial chemistry, genomics and proteomics at the drug discovery and development phase. It also shows at the discovery phase some of the main platform technologies, such as high through put screening (HTS) and bioinformatics.

Rather than originating within the large pharmaceutical companies, most of these innovations spawned a new set of specialist start up companies (Figure 2). As Galambos and Sturchio (1998) comment that:

It was, for instance, the first twentieth-century transition in this industry in which the initial stages of applied research and commercial development were centred in small, startup 
companies rather than the large, well financed organisations that have for many decades been the primary innovators in pharmaceuticals. (p 252)

Figure 2. Pharmaceutical Industry Value Chain and the Set of Specialist Firms

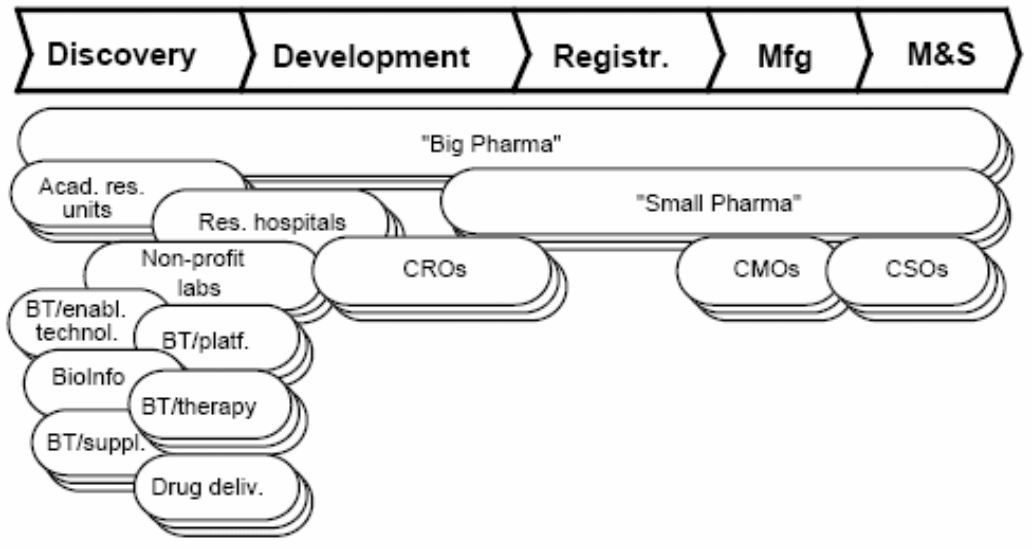

Source: Granberg and Stankiewicz (2002).

Figure 2 shows, in an industry value chain format, how these specialist technologies have generated an array of new specialist companies. These companies range from those focusing on drug discovery and development to those providing platform technologies. In addition, specialist companies in clinical trials (CROs), contract manufacturing (CMOs) and sales organisations (CSOs) have emerged. These companies comprise a complex value network providing services to one another, through alliances and market transactions as well as supplementing the knowledge base of the pharmaceutical companies.

While these two charts show the way in which the pharmaceutical industry structure has been transformed by the specialist firms, it also illustrates the way in which fully the integrated pharmaceutical company has remained active across the whole value chain. While the fully integrated model has become more complex, through the formation of many alliances, pharmaceutical companies have retained their capabilities across the each of the major value chain activities of drug discovery, development, manufacturing and distribution.

Arora, Fosfuri and Gamberdella (2001, p67) suggest that the industry is consolidating 'toward a structure in which an upstream industry of specialised technology suppliers has become a stable source of new products and technologies....to the downstream producers'. Orsengio et al. 2001 have also argued that the specialists have found it difficult to modify their structural position in this hierarchy and that the 'early entrants have enjoyed significant first mover advantages, precisely because they have been able to embody knowledge at a high level of generality’ (p501).

Another dynamic is the constantly changing technological regime. Biotechnology and its potential application to produce new biopharmaceuticals are constantly evolving and Teece's concept of 'dynamic capabilities' has clear application to the predicament of pharmaceutical companies. They must be constantly evaluating new technologies so as to adjust their internal and external competences to a rapidly evolving environment. 
The impact of biotechnology on the value chain and network of pharmaceutical companies has been substantial. As predicted by the resource based view, the strategic assets of biopharmaceutical firms has been accessed through alliances, which has extended the scope of the pharmaceutical value chain and incorporated it into a complex value network. This is also consistent with cost transaction economics for irregular transactions involving specific assets with high levels of uncertainty. This applies to many drug development projects and platform technologies as well. In some cases however the pharmaceutical company may decide on integration. One prominent case is the purchase of Rosetta, a leading bioinformatics company, by Merck. Perhaps contributing to this decision was the need for frequent interaction to make maximum use of the new technology, which made acquisition more cost effective.

While the pharmaceutical company has adapted its value chain to the opportunities afforded by biotechnology, it has retained its integrated structure. This emerging relationship between the specialist firms and pharmaceutical companies has led some observers to suggest that the core competitive advantage possessed by global pharmaceutical companies is their organisational and resource management capabilities to develop and distribute new pharmaceutical products (Kay 2001). While this view appears to ignore the considerable value of the specialist knowledge assets possessed by pharmaceutical companies, it does highlight the significance of being the integrator in an increasingly complex value network.

\section{Cost and profit potential}

The costs of developing biopharmaceuticals are about the same as for traditional pharmaceuticals. After various adjustments, DiMasi and Grabowski (2007) estimate that the cost is just $6 \%$ lower. Hoped for savings from more targeted clinical trials have not to date eventuated. This means that the economics of producing biopharmaceuticals, such as high sunk costs still holds. There is no evidence either that the extent of skewness in the returns is likely to be any different. Sales of a small number of blockbusters continue to dominate sales of biopharmaceuticals. These factors suggest that the advantages accruing to firms of large size will continue. Indeed overall most indicators suggest that pharmaceutical companies remain financially successful despite the challenges of modern biotechnology.

Aspects of the impact of biotechnology that are still to develop however centre on the distribution of relational rents from alliances formed between pharmaceutical and biopharmaceutical companies which may erode the returns from sales by the pharmaceutical companies In addition the manufacture of biopharmaceuticals is typically more difficult and more expensive than small molecule drugs. This may also act to lower profitability from biopharmaceutical sales.

\section{Competitive Strategy}

In the post biotechnology period, the main strategic issue facing pharmaceutical firms is how best to acquire access to the new technology. Galabos and Sturchio (1998) have identified two strategies adopted by large pharmaceutical companies to build absorptive capacity to gain access to the new genetics based rDNA technologies. One was to develop an expertise in a highly specific field with a view to generalising it 
across a range of therapeutic areas. The second was to build or acquire general capabilities through licensing and equity relationships with emerging biotechs.

Those at the forefront of the first strategy gained a competitive advantage. Eli Lily was the first to contract both with the biotech, Genentech and university researchers at Berkeley to acquire access to the new recombinant technology for insulin. Insulin was the first recombinant drug approved by the FDA and secured Eli Lily's continuing dominance of that market. Similarly Merck contracted William Rutter at the University of California, San Francisco to produce the first recombinant vaccine, Recombivax for hepatitis B, approved by the FDA in 1986 (Galambos and Sturchio 1996; Chandler 2005). Being in this leading position gave Merck and Eli Lily considerable advantages (Chandler 2005).

Roche adopted the second strategy, purchasing 60\% of Genentech's equity for \$2.1 billion in 1990, the first biotech to be established and one of the most successful. For late entrants however, access to the new technologies has been expensive. For instance, American Home Products (now Wyeth) paid $\$ 9.7$ billion in cash for American Cyanamid in 1994 to provide it with a learning base for the innovative technologies of the 1970s and 1980s (Chandler 2005, p227). Rather than outright purchase, a less expensive option was forming alliances with biopharmaceutical companies with the targeted technology. Pharmaceutical companies have sought both platform technologies and involvement in drug discovery projects through alliances.

Nonetheless for much of the period since the introduction of modern biotechnology to the industry, the extent to which the large pharmaceutical companies applied its resources to acquiring access to the new technologies presented most with a considerable dilemma. The relatively new, but pre biotechnology areas of microbial biochemistry and enzymology, were providing a steady stream of valuable new drugs. Companies were reluctant to abandon these projects in favour of those based on the much less well understood (and higher risk) recombinant rDNA technologies (Galambos and Sturchio 1998). Merck resolved this dilemma by focussing 'its use of biotechnology on supporting its core competencies in developing small organic molecules as drugs' (Galambos and Sturchio 1998, p268).

\section{Conclusion}

The purpose of this paper has been to analyse the traditional pharmaceutical business model and examine how it has changed with the impact of biotechnology. It has demonstrated that the adoption of the large fully integrated business model is largely the outcome of the economics of traditional pharmaceutical drug discovery, development and distribution methodologies. This has included economies of scale and scope, sunk costs and the advantages of the integrated value chain. Pharmaceutical companies have a powerful value proposition, which combined with patent protection, provides considerable pricing power. Despite the difficulties and complexities of distributing drugs and the skewed returns achieved by the revenue model, pharmaceutical companies using this business model have achieved above average profitability

In considering the impact of biotechnology most of the reasons for the large integrated model remain. Moreover the impact has been muted by the relatively low proportion 
of biopharmaceutical sales as a proportion of total sales by the largest pharmaceutical companies. The largest impact appears to be on the structure of the value chain and value network. The value network has become significantly more complex as many specialist technologies have become integrated into the pharmaceutical value chain. At the same time the pharmaceutical companies have remained substantially in control of the value chain, while gaining access to a wide range of complementary assets. It is not clear how the relational rents are being shared between the pharmaceutical companies and the specialist firms.

Although the proportion of new biopharmaceuticals drugs is increasing, the total numbers remain relatively small, so their sales remain a relatively small proportion of total sales. This means that the impact on key aspects of the business model including the value proposition, market segments, pricing and revenue model are still difficult to assess. Typically biopharmaceuticals are expensive to manufacture, about as expensive to develop and more likely to be targeted at smaller market segments. The effect on pricing and reimbursement of large numbers of biopharmaceuticals remains uncertain for the future of the business model.

Despite these challenges and uncertainties, the fully integrated pharmaceutical business model has endured, albeit in somewhat modified form. The powerful value proposition of the pharmaceutical companies can incorporate biopharmaceuticals and the advantages of scale, resources, in house manufacturing and global distribution reach do not appear to have been diminished by the new technologies.

\section{References}

Achilladelis, B. 1999, 'Innovation in the Pharmaceutical Industry,' Pharmaceutical Innovation, Chemical Heritage Foundation, Philadelphia.

Amit, R. and Shoemaker, P. 1993, 'Strategic assets and organizational rent', Strategic Management Journal, vol. 14, pp. 33-46.

Arora, A., Fosfuri, A. and Gambardella, A. 2001, Markets for Technology: The Economics of Innovation and Corporate Strategy, MIT Press, Cambridge, Mass.

AstraZeneca 2001, ‘AstraZeneca Approach to E-Business’, presentation to analysts, New York.

Baumol, W. and Willig, R. 1981, 'Fixed costs, sunk costs, entry barriers, and sustainability of monopoly’, Quarterly Journal of Economics, vol. 95, pp. 405-431.

Berndt, E. R., Bui, L., Reiley, D. and Urban, G. 2001, 'Information, Marketing and Pricing in the US Antiulcer Drug Market,' Information, Educating, and Marketing in Healthcare, Vol. 85, No. 2, pp100-105.

Blumberg, D. and Perrone, F. 2001, 'How Much are Marketing and Sales Capabilities Really Worth? A European Study on How the Capabilities Drive Performance', Accenture, www.acenture.com

Burgleman, R., Maidique, M. and Wheelwright, S. 2001, Strategic Management of Technology and Innovation, McGraw Hill, Boston.

Chandler, A. 1990, Scale and Scope: The Dynamics of Industrial Capitalism, Harvard University Press, Cambridge, Mass. 
Chandler, A. 2005, Shaping the Industrial Century: The Remarkable Story of the Evolution of the Modern Chemical and Pharmaceutical, Harvard University Press, Cambridge, Mass.

Chesbrough, H. 2006, 'Open innovation: A new paradigm for understanding industrial innovation', in H. Chesbrough, W. Vanhaverbeke and J. West, (eds), Open Innovation: Researching a New Paradigm, Harvard University Press, Cambridge, Mass.

Chesbrough, H. and Rosenbloom, R. S. 2002, 'The role of the business model in capturing value from innovation: Evidence from Xerox Corporation's technology spin-off companies', Industrial and Corporate Change, vol. 11, pp. 529-555.

Cockburn, I. 2004, 'The changing structure of the pharmaceutical industry', Health Affairs, vol. 23, no.1, pp. 10-22.

Cockburn, I. and Henderson, R. 2001, 'Scale and scope in drug development: Unpacking the advantages of size in pharmaceutical research', Journal of Health Economics, vol. 20, no. 6, pp. 1033-1057.

DiMasi, J. Grabowski, H. 2007, 'The Cost of Biopharmaceutical R\&D: Is Biotech different?' Managerial and Decision Economics, Vol. 28, Issue 4-5, John Wiley \& Sons, Ltd.

Galambos, L. and Sewell, J.E. 1995, Networks of Innovation: Vaccine Development at Merck, Sharp \& Dohme, and Mulford, 1895-1995, Cambridge University Press, New York.

Galambos, L. and Sturchio, J.L. 1998, 'Pharmaceutical firms and the transition to biotechnology: A study in strategic innovation’, Business History Review, vol. 72, pp. 250-278.

Gambardella, A. 1995, Science and Innovation: The US Pharmaceutical Industry during the 1980s, Cambridge University Press, New York.

George, P. and Perrone, F. 2001, 'How Much are Marketing and Sales Capabilities Really Worth? What Every Pharmaceutical Executive Should Know, the US Study', Accenture, www.acenture.com

Grabowski, H. and Vernon, J. 2001, 'Pressures from the demand side: Changing market dynamics and industrial structure', in H. Kettler (ed.) Consolidation and Competition in the Pharmaceutical Industry, based on papers delivered at the OHE Conference, London 16 October 2000, Office of Health Economics, London.

Grabowski, H., Vernon, J. 1994, 'Innovation and structural change in pharmaceuticals and biotechnology', Industrial and Corporate Change, vol. 3, pp. 435-449.

Granberg, A. and Stankiewicz, R. 2002, 'Biotechnology and the transformation of the pharmaceutical value chain and innovation system', paper presented at the Medicon Valley BioConference, Medicon Valley Academy, Copenhagen, 8-10 October 2002.

Grossman, S. and Hart, O. 1986, 'The costs and benefits of ownership: A theory of vertical and lateral integration', Journal of Political Economy, vol. 94, no. 4, pp. 691-719.

Hart, O. and Moore, J. 1990, 'Property rights and the nature of the firm', Journal of Political Economy, vol. 98, no. 6, pp. 1119-1158. 
Harvard Business School (HBS) 1999, 'From the Field: Inside Biotechnology and Pharmaceuticals', HBSP No. 4924, Harvard Business School Press, Boston.

HBS 2000, From the Field: Inside Biotechnology and Pharmaceuticals, HBSP No. 4924, Harvard Business School Press, Cambridge, Mass.

Henderson, R. and Cockburn, I. 1996, 'Scale, scope and spillovers: The determinants of research productivity in drug discovery’, Rand Journal of Economics, vol. 27, no. 1, pp. 32-59.

Kay, J. 2001, 'Changes in market structure: The economic issues', in H. Kettler (ed.), Consolidation and Competition in the Pharmaceutical Industry, Office of Health Economics (OHE), London.

Landall, R., 1999, 'Introduction', in R. Landau, B. Achilladelis and A. Scriabine, Pharmaceutical Innovation, Chemical Heritage Press, Philadelphia.

Lichtenberg, F. 1996, 'The Effect of Pharmaceutical Utilization and Innovation on Hospitalization and Mortality (HE PR)', NBER Working Paper No. 5418, National Bureau of Economic Research, Cambridge, Mass.

Malknight, T. 1999, 'Eli Lilly, 1998 (A): Strategic challenges’, 9-399-173, Harvard Business School Publications and IMD International, Boston.

March, J.G. and Simon, H.A. 1958, Organizations, John Wiley, New York.

Mercer Management Consulting 2001, 'Where are the next profit zones in pharmaceuticals? The blockbuster model will begin to yield winners and losers', Boston.

Merck 2003, Annual Report 2003, New York.

Mowery, D. 1983, 'The relationship between intrafirm and contractual forms of industrial research in American manufacturing, 1900-1940', Explorations in Economic History, vol. 20, pp. 351-374.

Orsenigo, L., Pammoli, F. and Riccaboni, M. 2001, 'Technological change and network dynamics: Lessons from the pharmaceutical industry', Research Policy, vol. 30, pp. 485-508.

Pharmaceutical Research Manufacturers of America (PhRMA) 2006, Pharmaceutical Industry Profile 2006, Washington DC.

Prahalad, C. and Hamel, G. 1990, 'The core competence of the corporation', Harvard Business Review, May-June, pp. 79-91.

Rasmussen, B. 2007a, 'Trends in Biopharmaceutical Alliances for the Key Business Models', Pharmaceutical Industry Project Working Paper No. 37, December, Centre for Strategic Economic Studies, Victoria University, Melbourne.

Rasmussen, B. 2007b, 'Business Models and the Theory of the Firm', Pharmaceutical Industry Project Working Paper No. 32, June, Centre for Strategic Economic Studies, Victoria University, Melbourne.

Reinhardt, U.E. 2001, 'Perspectives on the pharmaceutical industry', Health Affairs, vol. 20, pp. 136-149.

Rosenberg, N. 1990, 'Why do firms do basic research (with their own money)?, Department of Economics, Stanford University, Stanford, Calif. 
Sampat, B.N. 2006, 'Patenting and U.S. academic research in the 20th century: The world before and after Bayh-Dole’, Research Policy, vol. 35, no. 6, pp. 772-789.

Scherer, F., Harhoff, D. and Kukies, J. 2000, 'Uncertainty and the size of distribution of rewards from innovation', Journal of Evolutionary Economics, vol. 10, pp. 175200.

Sutton, J. 1991, Sunk Costs and Market Structure: Price Competition, Advertising, and the Evolution of Concentration, MIT Press, Cambridge, Mass.

Teece, D., Pisano, G. and Shuen, A. 1997, 'Dynamic capabilities and strategic management’, Strategic Management Journal, vol. 18, no. 7, pp. 509-533.

Teece, D.J. 1986, 'Profiting from technological innovation: Implications for integration, collaboration, licensing and public policy', Research Policy, vol. 15, no. 6, pp. 285-305.

Walsh, G. 2002, 'Biopharmaceuticals and biotechnology medicines: An issue of nomenclature', European Journal of Pharmaceutical Sciences, vol. 15, pp. 135138.

Walsh, G. 2006, ‘Biopharmaceutical benchmarks 2006’, Nature Biotechnology, vol. 24, no. 7, pp.769-778.

Walton, J. 2001, 'Investors' views on Merger and acquisition, alliance and licensing activity in the pharmaceutical industry', in H. Kettler (ed.), Consolidation and Competition in the Pharmaceutical Industry, based on papers delivered at the OHE Conference, London, 16 October 2000, Office of Health Economics, London.

Williamson, O. 1971, 'The vertical integration of production: Market failure considerations', American Economic Review, vol. 61, no. 2, pp. 112-123.

Williamson, O. 1981, 'The modern corporation: Origins, evolution, attributes', Journal of Economic Literature, vol. 19, December, pp. 1537-1568. 